Paris VII, under the Rectorship of Professor Alliot, a Centre for teaching and research in African Studies was inaugurated in December 1970.

The Centre will endeavour, within the framework of the study of the relations between the major cultural areas and the political systems of Africa, to develop programmes of inter-disciplinary research and to promote collaboration between African research workers and other Africanists for the better understanding of their respective approaches, research methods, and organization.

A General Assembly, including all the teaching and research staff and other specialists, will review the work of a scientific committee and of a directorate nominated by the General Assembly. Seminars organized in five sections are being planned: ecology and history; linguistics; religion and art; economics and urbanization; political and juridical systems. The Centre hopes to establish a special library together with photographic, tape recording and film collections and may provide for the publication of studies and of a periodical review.

\title{
Northwestern University: Program of African Studies
}

A 'Report to the Ford Foundation 1969-70 on the Program of African Studies and the National Unity Grant' surveys work in this field at Northwestern University. The aim has been to assist the training of scholars in their respective disciplines to focus these on the study of aspects of African life and development relevant to their particular research and teaching interests. Students enrolled in the Program receive academic degrees through their own departments. The Program itself and the Graduate School award a Certificate of African Studies to those who demonstrate competence in African material handled in four different disciplines, in interdisciplinary approaches related to field-work, and in African language or linguistics. Since 1939 over 100 scholars, including an increasing number of Africans, have completed doctoral requirements. As far as possible faculty members and graduate students are aided in securing field research experience in Africa.

Courses and seminars have been extended to additional disciplines and areas. These now include the arts, archaeology, philosophy, law, psychology, and education, and take in the territories of North Africa, the Horn, and southern Africa. Northwestern's professional schools of law, business, technology, and education have shown concern and support for African studies and in recent years students have also played an important part in the functioning of the Program. A Certificate in African Studies for undergraduates is now under consideration.

A co-operative inter-university Program in Ethiopian Studies between Northwestern, the University of Chicago, and the University of Illinois, Chicago Campus (see Africa, xxxviii. 3, 1968, p. 345) has brought Ethiopian scholars to work at Northwestern and the University Law School has carried out field studies in Ethiopia and Zambia. The scheme for bringing scholars from Africa under National Unity grants has had rewarding results. Research being currently undertaken by various departments at Northwestern includes: the impact of administrative reforms introduced in Kano in 1969 , and study of a collection of over 2,000 Hausa and Arabic manuscripts (Dr. John Paden); society, culture, and development in Nairobi (Professor Ronald Cohen); African workers in Katanga (Dr. Johannes Fabian); national unity in the Cameroon Republic; urban life styles in Douala, Yaounde, and Abidjan (Professor Remi Clignet); the social and economic profile of teachers in urban centres in East and West Cameroon (Professor Remi Clignet and Professor Philip J. Foster).

The Africana collection of the University Library has been named officially the Melville J. Herskovits Library of African Studies in honour of the founder and first director of the Program of African Studies. 
The general survey of the work of the African Studies Program is followed by appendices listing Ph.D.s from 1939 to 1970 ; students undertaking dissertation research 1970-I; subjects and status of Ph.D. dissertations, October 1970; Fellowships 1970-1; and Courses with African content $1969-70$.

Copies of the report may be obtained from the Program of African Studies, Northwestern University, 1813 Hinman Avenue, Evanston, Illinois.

\section{Research Conference: Afro-American Societies and Cultures}

Tre U.S. Social Science Research Council committee, under the chairmanship of Sidney W. Mintz, held its first research conference, on continuities and discontinuities in AfroAmerican societies and cultures, on 2-4 April 1970 at the University of the West Indies, Jamaica, with the aid of the Wenner-Gren Foundation for Anthropological Research. The first session was on Afro-American societies and cultures in hemispheric perspective; the second on social organization; the third on religious behaviour; and the fourth on languages and socio-linguistics. Details of the papers presented may be found in Items, vol. 24, no. 3, September 1970, pp. 30-1.

\section{Conference on Urban Growth in Black Africa and Madagascar, ig September- 2 October 1970, at Talence, France}

Thrs Conference, sponsored by the Centre National de la Recherche Scientifique in conjunction with ORSTOM, was undertaken by the Centre d'Études de Géographie Tropicale at the University of Bordeaux at Talence. The Centre provided an excellent setting for a meeting of over Ioo geographers and other social scientists under the Presidency of Professor Pierre Gourou, the doyen of francophone gengraphers of the tropics. The Conference was addressed by Professor Jacqueline Beaujeu-Garnier on ' Urban Growth in Tropical Lands'. Papers which had been invited had previously been made available to Conference participants and provided the background for the remainder of the proceedings. Fourteen major topics were presented for discussion and each of these was introduced by a general report. They ranged widely and included the facts and processes of urban growth, differentiation in urban societies, the tole of industry and handicrafts, problems of employment, urban typology and morphology, inter- and intra-urban relations, and the health of immigrants in towns. For the most part there was a lack of satisfactory conceptual frameworks into which the detailed material might be fitted. For example, while a great deal of information was presented on various towns, particularly in francophone Africa, little emerged in respect of similarities and differences among them. To some extent this lack of conceptual framework was compensated for in the discussions. The Conference provided an opportunity for renewing contacts and for making a large number of new ones, particularly with many French, Belgian and francophone African colleagues for the smaller number of geographers from elsewhere. There were representatives from anglophone Africa, from Germany, U.K., and U.S.A. Apart from the academic activities of the meeting, participants enjoyed the hospitality of CNRS and the University and City of Bordeaux. Both the academic and social arrangements were admirably organized and conducted by Professor Guy Lasserre, Director of the Centre d'Études de Géographie Tropicale, ably seconded by Professor Pierre Vennetier, and supported by other colleagues. The papers submitted to the Conference, together with introductory statements and subsequent discussions, will be published in due course by CNRS.

(Communicated by Dr. R. Mansell Prothero) 